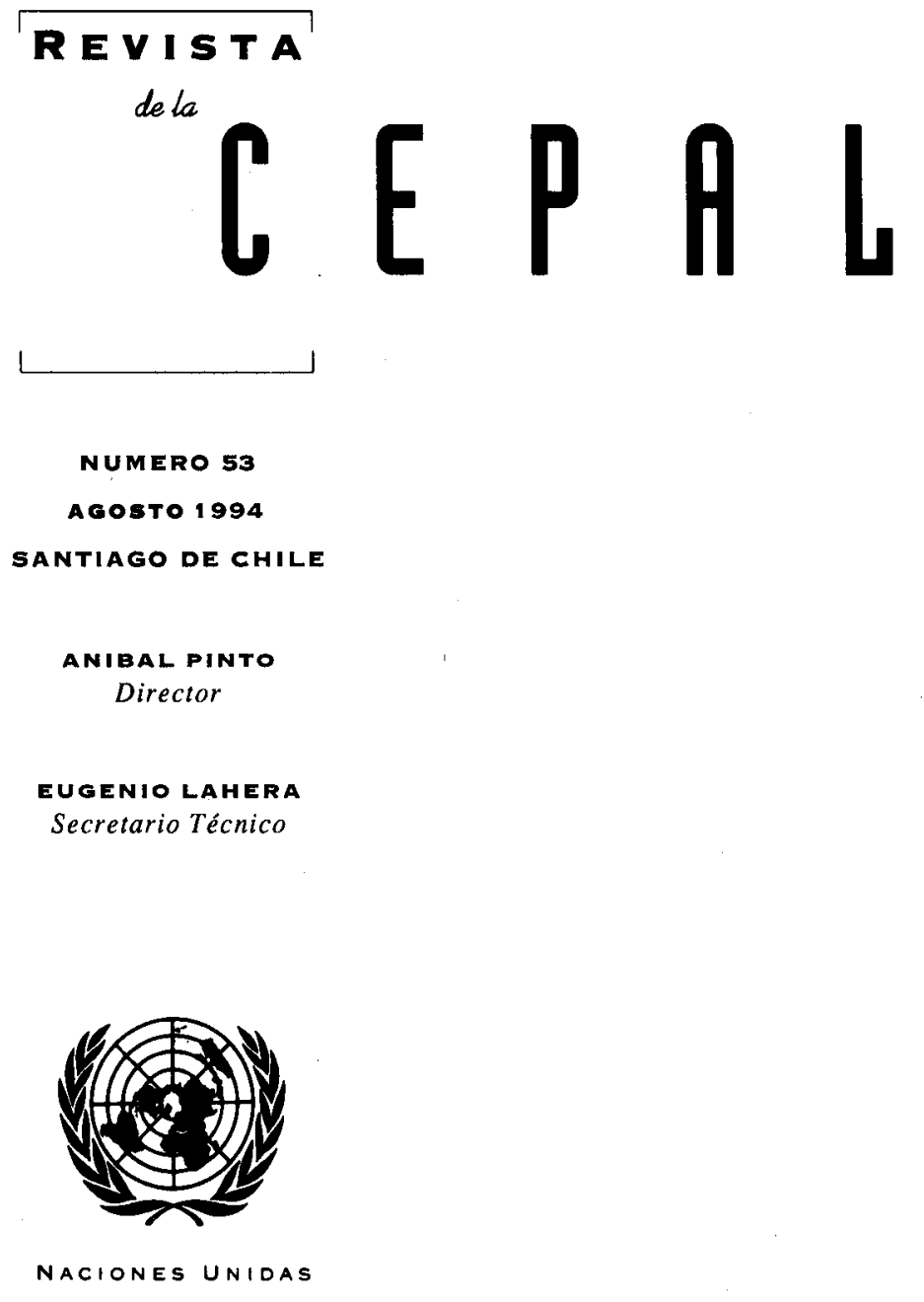


América Latina y el Caribe frente a la economía mundial

Gert Rosenthal

Afluencia de capitales externos y políticas macroeconómicas

Andras Uthoff y Daniel Titelman

Represión fínanciera y patrón de financiamlento latínoamericano

31

Marcos Antonio Macedo Cintra

Políticas de competitividad

49

Wilson Peres

Política industrial y fomento de la competitividad

Osvaldo Rosales

El regionalismo abierto y la integración económica

Juan A. Fuentes $K$.

Transformaciones del trabajo femenino urbano

91

Irma Arriagada

La gestión del agua y las cuencas en América Latina

Axel Dourojeanni

Políticas públicas y competitividad de las exportaciones

agrícolas

Milton von Hesse

Agroindustria y transformación productiva de la pequeña agricultura

Alejandro Schejtman

Grupos privados nacionales en México, 1988-1993

Celso Garrido

Evolución y perspectivas de la reforma y la apertura en China 


\title{
América Latina y el Caribe frente a la economía mundial
}

\author{
Presentación del Secretario Ejecutivo de la CEPAL, \\ señor Gert Rosenthal, al inaugurar \\ el vigésimoquinto período de \\ sesiones de la Comisión, celebrado \\ en Cartagena de Indias, Colombia, del 20 al \\ 27 de abril de 1994.
}

Sean mis primeras palabras para expresar nuestro reconocimiento al pueblo y al Gobierno de Colombia y, en especial, al Presidente César Gaviria.

Primero, por el constante apoyo que han brindado a las Naciones Unidas en general, y a la Comisión Económica para América Latina y el Caribe en particular, como lo manifiestan su activa y constructiva participación en nuestros foros, su actitud solidaria para con la Secretaría y su demostrada vocación por la cooperación internacional.

Segundo, por haber colaborado tan estrechamente con la Secretaría en los aspectos sustantivos y organizativos de la preparación de este encuentro. La eficiencia con que se desarrollaron las actividades a nivel técnico de este vigésimoquinto período de sesiones da testimonio del extraordinario ahínco y dedicación de nuestros anfitriones. El apoyo que hemos recibido de la Ministra de Relaciones Exteriores, Noemí Sanín de Rubio, y del Ministro de Comercio Exterior, Juan Manuel Santos, así como de sus colaboradores, compromete nuestro sincero reconocimiento.

Tercero, por su feliz iniciativa de convocarnos a Cartagena de Indias, donde las modernas e impecables instalaciones de este Centro de Convenciones se conjugan con el aura de tiempos pasados y el recuerdo de distintas épocas históricas de este crisol que es la región de América Latina y el Caribe. Resulta difícil imaginar un escenario más acogedor que el que nuestros amigos colombianos han puesto a nuestra disposición, realzado por el calor humano tan propio de ellos.

Por todo esto, y por la presencia del Presidente Gaviria entre nosotros, muchísimas gracias. 
Hace ya cuatro años que concluyó la década de la gran crisis del desarrollo latinoamericano. Esta dejó entre sus muchos legados la profundización del conocimiento en los ámbitos de la gestión macroeconómica y de la modernización productiva, pero, como contrapartida, un importante cúmulo de rezagos sociales que afecta a una proporción significativa de la población latinoamericana y caribeña. Nuestra Secretaría se ha propuesto capitalizar ese legado y poner a disposición de los formuladores de política elementos de juicio que faciliten la superación de la crisis y de esos rezagos sociales. Nuestra respuesta, cuya entrega inicial vio la luz también hace cuatro años, está contenida en el planteamiento titulado Transformación productiva con equidad. Este era apenas el inicio de una nueva etapa de reflexión sobre cómo abordar, con un enfoque sistémico, la compleja tarea de crecer, distribuir, defender el medio ambiente y consolidar la democracia, todo ello de la manera más simultánea posible. Señalamos entonces, y lo reiteramos ahora, que la posibilidad de cumplir todas esas tareas depende decisivamente de una mejor inserción de los países latinoamericanos y caribeños en la economía mundial.

Al emprender aquel proceso de reflexión, la Secretaría no sólo pretendía satisfacer una necesidad objetiva, dado el ambiente de perplejidad que generó el cuestionamiento de estrategias de desarrollo impugnadas por nuevas realidades. También buscaba retomar el papel institucional que históricamente ha correspondido a la CEPAL - la Secretaría y su principal foro intergubernamental - como una instancia orientadora del desarrollo latinoamericano y caribeño.

Mucho se ha avanzado en estos cuatro años, tanto en el esclarecimiento de ideas como en el logro de metas concretas.

En cuanto a lo primero, hoy entendemos mejor que antes los elementos centrales de una buena gestión macroeconómica, el efecto regresivo de un ajuste desordenado y recesivo, la importancia de la política microeconómica, el vínculo entre desarrollo y medio ambiente, así como la naturaleza de la innovación y su aplicación al proceso productivo. También se ha ahondado en el análisis de las complementariedades y las oposiciones entre políticas que buscan el crecimiento y aquéllas centradas en la equidad.

En lo que se refiere a las metas, el panorama económico de la región ha cambiado considerablemente en los últimos años. En distinto grado, entre un país y otro, los desequilibrios macroeconómicos característicos del decenio anterior comenzaron a ceder; la transferencia negativa de recursos financieros se convirtió en una afluencia neta de capitales externos; el sector exportador creció y se diversificó, y la actividad económica en su conjunto exhibió un modesto repunte, sobre bases cualitativamente distintas de las que existían hace apenas unos años. Así, el ambiente de abatimiento de los años ochenta ha dado paso a la efervescencia de los noventa.

Nuestra institución, y en especial este foro, ha influido sobre estos acontecimientos, y a la vez ha recibido su influjo, al interpretar la naturaleza de los fenómenos en curso, recoger las riquísimas experiencias que se han dado en los diversos países de la región y ponerlas a disposición de todos, y asimismo al formular propuestas de acción para acceder al desarrollo y promover la cooperación intrarregional e internacional. 
Sin embargo, así como los avances en el desempeño económico resultaron insuficientes y parciales, la tarea de aggiornamento de nuestro marco conceptual está muy lejos de haber concluido. Es más, esa labor debe concebirse como un proceso permanente, sobre todo ante la necesidad de adaptar el pensamiento económico a las rápidas mutaciones que América Latina y el Caribe enfrentan dentro de la región y, más importante aún, en el resto del mundo.

Es por eso que en esta ocasión hemos elegido continuar nuestra reflexión colectiva con un tema de especial relevancia para América Latina y el Caribe: los requerimientos que cada país de la región debe cumplir para interactuar dinámicamente con el resto del mundo. Este aspecto ya fue objeto central de atención en los planteamientos pioneros de la CEPAL y en muchos de sus trabajos posteriores. Sin embargo, la vinculación económica externa adquiere hoy un significado radicalmente distinto del pretérito, en el contexto de la globalización de la economía.

Nuestra indagación fue guiada por dos vectores: primero, la interacción de cada país latinoamericano y caribeño con los demás en el ámbito de la integración regional (y, eventualmente, hemisférica); segundo, la interacción de cada uno de ellos con la economía extrarregional. Ambos temas están íntimamente interrelacionados, ya que los compromisos integradores contemporáneos pueden y deben contribuir a mejorar la inserción internacional de los países de la región, a la vez que una mayor participación en la economía internacional tendrá que fortalecer los vínculos intrarregionales de interdependencia económica.

Durante la fase técnica la Secretaría ya ha tenido la oportunidad de exponer el contenido de los dos documentos principales sometidos a la consideración de este período de sesiones. Sin embargo, quisiera insistir sobre seis aspectos cuyo esclarecimiento consideramos imprescindible. Estos no sólo son cruciales para el futuro desarrollo de los países de la región, sino que se ubican en un espacio insuficientemente explorado: el de la intersección de las políticas de corto plazo con las de mediano y largo aliento.

En primer lugar, tal y como hemos venido insistiendo desde 1990, el logro de la competitividad internacional —como requisito ineludible para crecer sostenida y sustentablemente y mejorar la distribución del ingreso- exige un enfoque sistémico. Dicho de otra manera, es necesario superar múltiples escollos en forma simultánea, dentro de las empresas y también del sistema socioeconómico y físico en que éstas se insertan. Es por eso que en el documento que hemos aportado a este período de sesiones sobre políticas para mejorar la inserción de América Latina y el Caribe en la economía internacional, abordamos tanto la política macroeconómica como las micro y meso económicas, combinadas ambas con la política comercial. Por ejemplo, al examinar las riquísimas experiencias que se han dado en la región en el ámbito de la política comercial, centramos la atención no sólo en su contenido específico y su horizonte temporal de aplicación, sino también en su articulación con otras políticas macro y microeconómicas.

En ese orden de ideas, la modernización de las políticas comerciales no se agota con la progresiva eliminación de las restricciones a la importación. Junto con ello es necesario formular una estrategia de integración a los mercados internacionales $\mathrm{e}$ instrumentarla mediante un conjunto de orientaciones y medidas 
coherentes que, con vigor y persistencia, favorezcan las actividades productivas de bienes y servicios con potencial exportador, faciliten la reestructuración de la base sustitutiva de importaciones y mejoren la competitividad sistémica.

En segundo lugar, un tema en el que hasta ahora no se ha profundizado lo suficiente en el marco sistémico aludido es el vínculo entre las políticas comercial y la financiera -o bien, si se prefiere, entre la cuenta corriente y la cuenta de capital del balance de pagos-, vista la innegable influencia de los ingresos de capital sobre la eficiencia en la asignación de recursos por intermedio de dos variables claves: el tipo de cambio real en el mercado cambiario y la tasa de interés real en el mercado monetario. Nuestra conclusión indica que, en general, la liberalización del comercio y la del mercado financiero interno deben preceder a la liberalización de la cuenta de capital, y que en todo caso, previamente a ésta, cabría cumplir algunos requisitos atinentes a la coherencia global de la política macroeconómica y a la regulación de los mercados financieros.

En tercer lugar, el vuelco de la tendencia del financiamiento externo neto no siempre se ha reflejado de manera proporcional en los niveles de inversión. En años recientes, el crecimiento del coeficiente de inversión fue significativamente más bajo que el incremento del ingreso de recursos externos, porque una parte de éstos debió destinarse a compensar el deterioro de los términos del intercambio, y otra se utilizó para financiar un mayor consumo, en particular de bienes importados.

En cuarto lugar, América Latina y el Caribe deben prepararse para actuar en la economía internacional tal como ésta es, y no como quisieran que fuese. En este sentido, si bien es evidente que el esfuerzo exportador de los países de la región sería facilitado por una coyuntura externa favorable, con una economía internacional en expansión, un régimen comercial abierto y transparente y un acceso adecuado tanto al financiamiento como a la tecnología, ello no obsta para que el contenido y alcance de las políticas internas destinadas a mejorar la inserción en la economía mundial también desempeñen un papel fundamental. Esta es otra forma de decir que mejorar la inserción internacional de las economías de la región depende tanto de la coyuntura externa — sobre la que acaso sólo podemos influir marginalmentecomo del esfuerzo interno y regional, que sí admite la puesta en práctica de acciones y estrategias deliberadas y concertadas.

En quinto lugar, al superarse el debate de antaño en el que los países en desarrollo atribuían el pobre desempeño de sus economías a la desfavorable coyuntura internacional, en tanto que las naciones desarrolladas lo imputaban a una gestión económica deficiente, se amplía el potencial de las Naciones Unidas para contribuir a la cooperación internacional. Esto es posibilitado por un ambiente que contrasta con el generado por aquel debate y por el tono de denuncia que lo acompañaba, que frecuentemente contribuía a la polarización de posiciones en detrimento de una constructiva cooperación.

En sexto lugar, de las anteriores consideraciones surge nuestro planteamiento sobre la integración latinoamericana y caribeña. En el fondo, en la propuesta que hemos denominado "regionalismo abierto" para América Latina y el Caribe, hemos procurado conciliar el objetivo de mejorar la inserción de los países de la región en la economía mundial con el del pleno aprovechamiento del potencial de la integración económica intrarregional; en otras palabras, promover una integra- 
ción que resulte funcional para mejorar la inserción internacional. Eso exige, sobre todo, prestar especial atención a las características de los compromisos integradores, ya que no cualquier acuerdo subregional o bilateral cumple con ese requisito.

Cabría aclarar, sin embargo, que el tipo de integración que proponemos es igualmente válido en una economía internacional más abierta y transparente que ante un mundo fragmentado en agrupaciones de países. Evidentemente, aspiramos a que se materialice el primero de estos escenarios, caso en el que los compromisos integradores constituirían los cimientos de un mundo libre de proteccionismo y de trabas al intercambio de bienes y servicios. Pero si ese escenario no llegara a darse por razones fuera del control de los países latinoamericanos y caribeños, proponemos que, por lo menos, la región misma se configure como una de esas agrupaciones para compensar algunos de los costos de un aislamiento aún mayor. El punto principal es que el "regionalismo abierto" permitiría a la región prepararse para una economía internacional abierta y transparente, sin renunciar a la posibilidad de utilizar la integración como mecanismo de defensa, si llegara a ser necesario.

Antes de concluir, debo recordarles que nuestra agenda no se limita a la interacción de cada país latinoamericano y caribeño con la región y con el mundo. También comprende otros temas que atañen más de cerca a la preocupación por que la transformación productiva se conjugue con la equidad. Así, nos abocaremos a presentar las aspiraciones colectivas de los países de la región ante la Cumbre Mundial sobre Desarrollo Social. Los objetivos de esa reunión coinciden con prioridades enunciadas en el pasado por la CEPAL, sobre todo en los ámbitos de la integración social, la generación de empleo y el combate contra la pobreza. Pienso que América Latina y el Caribe tienen mucho que aportar al éxito de esa conferencia, tanto en el aspecto analítico como en el de las experiencias prácticas. Asimismo, se espera que los resultados de la Cumbre legitimen la consideración de la equidad como una variable en el proceso de desarrollo.

En ese mismo orden de ideas, se someterá a la consideración de ustedes el Anteproyecto de Plan de Acción Regional Latinoamericano y del Caribe sobre Población y Desarrollo, fruto de varios encuentros subregionales y regionales realizados durante los últimos seis meses. Este documento habrá de complementar el Consenso Latinoamericano y del Caribe sobre Población y Desarrollo aprobado durante la Reunión Regional Latinoamericana y Caribeña Preparatoria de la Conferencia Internacional sobre la Población y el Desarrollo.

Asimismo, hemos continuado nuestra reflexión sobre cómo conciliar los objetivos de crecimiento y la equidad en un trabajo elaborado conjuntamente con la Organización Panamericana de la Salud, en el que se analizan los vínculos entre salud, transformación productiva y equidad. Esta tarea se enmarca en la preocupación por la inversión en recursos humanos ya planteada en trabajos anteriores que abordaban la educación y el conocimiento, y confiamos que facilitará una revalorización sobre la importancia de la salud en el proceso de desarrollo.

No obstante los múltiples obstáculos que dificultan el desarrollo en América Latina y el Caribe, hoy también existe una constelación de factores potencialmen- 
te favorables que podrían darle un notable impulso. Entre éstos se destacan la progresiva asimilación de lo aprendido a raíz del esfuerzo por aumentar y diversificar las exportaciones; la mejoría en la calidad de la gestión macroeconómica; la posibilidad de llenar lo que hasta ahora ha sido un vacío en el instrumental de políticas públicas de la región - la aplicación de políticas micro y mesoeconómicasdestinadas a aumentar la productividad de acuerdo con las mejores prácticas internacionales; el renovado acceso al financiamiento externo y el auge experimentado por la cooperación económica intrarregional.

La posibilidad de aprovechar estos factores y capitalizar los considerables logros de los últimos años da sentido a nuestro debate, que permitirá aclarar ideas y ofrecer orientaciones para la acción. Así, este encuentro en Cartagena de Indias nos brinda una nueva oportunidad para que nuestra Secretaría interactúe con sus gobiernos miembros y contribuya a impulsar tanto al proceso de desarrollo como a la cooperación internacional. Hoy nos proponemos dar un paso más en esa dirección, inspirados por la presencia de tan dignos representantes de nuestros Estados miembros y del Gobierno de Colombia. 